(C) 1981. The Genetical Society of Great Britain

\title{
ENVIRONMENTAL INDUCTION OF HERITABLE CHANGES IN FLAX: DEFINED ENVIRONMENTS INDUCING CHANGES IN RDNA AND PEROXIDASE ISOZYME BAND PATTERN
}

\author{
C. A. CULLIS \\ John Innes Institute, Colney Lane, Norwich NR4 7UH \\ Received: $22 . x i i .80$
}

\section{SUMMARY}

\begin{abstract}
A number of environments which induce changes in the rDNA amount and/or the peroxidase isozyme band pattern in the fiax variety "Stormont Cirrus" have been defined. A large number of environments induced changes in the rDNA amount, but only two induced changes in the peroxidase isozymes. The changes in peroxidase were not observed during growth of the plants under inducing conditions, but only in the progeny.
\end{abstract}

\section{INTRODUCTION}

Heritable changes can be induced in some flax varieties when they are grown in certain environments (Durrant, 1962, 1971). The initial observation was that stable forms differing in plant weight (large, L, and small, S, genotrophs) were produced in subsequent generations following the growth of the original (plastic, $\mathrm{Pl}$ ) variety in particular environments. These two stable genotrophs then behaved as genetically distinct lines in most respects.

In addition to the difference in plant weight the two stable genotrophs differed from one another in a number of other characters. These were height ( $\mathrm{L}$ was taller than S), nuclear DNA amount (L had 16 per cent more than S, (Evans, Durrant and Rees, 1966)), ribosomal DNA (rDNA) amount (L had 50 per cent more than S, (Cullis, 1975, 1976)), isozyme band pattern (Cullis and Kolodynska, 1975) and seed capsule septa hair number (L hairless, S. hairy) (Durrant and Nicholas, 1970).

The majority of the treatments used to induce heritable changes have involved growing plants in soil based composts or in soil although a series of experiments using nutrient solutions have also been reported (Durrant, 1971). In all these experiments the character used to determine whether or not heritable changes has been induced was plant weight (Durrant, 1962, 1971) and in certain instances nuclear DNA amount was also measured (Durrant and Jones, 1971).

In the experiments reported here rDNA amounts and the peroxidase isozyme band patterns were used as markers of heritable changes. The aims were to determine defined conditions under which heritable changes could be induced in these characters, the timing of the changes during the induction and the extent to which a single environment could induce changes in both these characters. 


\section{MAterials AND METHODS}

\section{(i) Plant Material}

Seed of the variety Stormont cirrus was obtained from Dr A. Durrant. Seed from two capsules were grown out of doors in John Innes potting compost No. 1 (JIP1) for two generations, the lines being kept separate.

\section{(ii) Growth of plants}

Plants of $\mathrm{Pl}$ were grown in the different nutrient environments in a controlled environment chamber at $20^{\circ} \mathrm{C}$ with a $16 \mathrm{hr} / 8 \mathrm{hr}$ light/dark cycle. Once the plants had set seed they were moved to a heated greenhouse. Plants were grown singly in either (a) a compost comprised of 7 parts soil, 3 parts peat, 2 parts granite chipping or (b) perlite/chick grit $(50 / 50 \mathrm{v} / \mathrm{v})$, in 5 " pots. In either case they were watered with the appropriate nutrient solutions at sowing and subsequently at weekly intervals. In the interim they were given only water. The progeny from the plants grown under inducing conditions were grown in 5 " pots in JIP1 in a heated greenhouse.

\section{(iii) Nutrient solutions}

The nutrient solutions used were:

$n-1$ per cent ammonium sulphate.

$p-1$ per cent solution of triple superphosphate prepared as described by Durrant (1962).

$k-1$ per cent solution of potassium chloride.

Where the letters appear in combination all those treatments were applied simultaneously.

Nutrient treatments applied to plants growing in perlite/chick grit were:

1. Hoaglands solution

2. $0 \cdot 1 \times$ Hoaglands macronutrients + complete micronutrients $+\mathrm{npk}$

3. Hoaglands solution containing complete macronutrients $+0 \cdot 1 \times$ micronutrients

4. Hoaglands containing $0 \cdot 1 \times$ macronutrients + complete micronutrients

5. $0 \cdot 1 \times$ Hoaglands solution

6. $0 \cdot 1 \times$ Hoaglands macronutrients + complete micronutrients $+\mathrm{nk}$.

\section{(iv) DNA preparation}

DNA was prepared from the leaves and apical buds as previously described (Cullis, 1979a).

\section{(v) Preparation and fractionation of labelled RNA}

Flax callus cultures, grown in liquid Murashige and Skoog medium (Murashige and Skoog, 1962) containing $5 \mu \mathrm{M}$ 6-benzylaminopurine and $0.01 \mu \mathrm{M}$ naphthylacetic acid, were labelled by the addition of $1 \mu \mathrm{Ci} / \mathrm{ml}$ $\left[{ }^{3} \mathrm{H}\right]$ uridine (Radiochemical Centre, Amersham) for $72 \mathrm{~h}$. The callus was washed in distilled water and homogenised in $30 \mathrm{mM}$ Tris- $\mathrm{HCl}(\mathrm{pH} \mathrm{9.0)}$, $0.15 \mathrm{M} \mathrm{NaCl}, 0.5$ per cent sarcosyl. The mixture was deproteinised with 
an equal volume of phenol/cresol $(500 \mathrm{~g}$ phenol, $70 \mathrm{ml}$-cresol, $0.5 \mathrm{~g}$ 8 -hydroxyquinone, $55 \mathrm{ml}$ water) and the nucleic acids precipitated with 95 per cent ethanol containing $0 \cdot 1 \mathrm{M}$ sodium acetate ( $\mathrm{pH} 5 \cdot 5$ ). The RNA was fractionated on 2.4 per cent polyacrylamide gels and the regions containing the two large rRNAs were sliced out and extracted separately with a medium containing $3 \mathrm{ml} 0.15 \mathrm{M} \mathrm{NaCl}, 0.1 \mathrm{ml} 10$ per cent sodium lauryl sulphate and $3 \mathrm{ml}$ phenol/cresol solution. After centrifugation at $3000 \times \mathrm{g}$ for $10 \mathrm{~min}$ the aqueous layer was removed, extracted with diethyl ether and used for hybridisation. The specific activity of the RNA was $10,400 \mathrm{cpm} / \mu \mathrm{g}$.

\section{(vi) Hybridisation}

DNA dissolved in $0 \cdot 1 \times \mathrm{SSC}$ at $5-10 \mu \mathrm{g} / \mathrm{ml}$ was denatured by the addition of $0 \cdot 1$ vol $1 \mathrm{~N} \mathrm{NaOH}$. After $15 \mathrm{~min}$ at room temperature the solution was neutralised by the addition of $0 \cdot 1 \mathrm{vol} \mathrm{HCl}$ and the salt concentration increased to $6 \times \mathrm{SSC}$. The denatured DNA was loaded onto $13 \mathrm{~mm}$ HAWP millipore filters (5-10 $\mu \mathrm{g} \mathrm{DNA} /$ filter). The filters were air dried and then baked at $80^{\circ} \mathrm{C}$ for 2 hours prior to use. The filters were incubated, 50 to a vial, in $5 \mathrm{ml} 6 \times \mathrm{SSC}$ containing labelled RNA at $7.5 \mu \mathrm{g} / \mathrm{ml}(5 \mu \mathrm{g} / \mathrm{ml} 25 \mathrm{~S}$ rRNA, $2 \cdot 5 \mu \mathrm{g} / \mathrm{ml} 18 \mathrm{~S}$ rRNA $)$ at $70^{\circ} \mathrm{C}$ for 4 hours. They were washed successively with $6 \times$ SSC, twice with $2 \times$ SSC containing $10 \mu \mathrm{g} / \mathrm{ml}$ RNase (for $15 \mathrm{~min}$ ), twice with $2 \times \mathrm{SSC}$ and then dried.

The radioactivity bound to the filters and the DNA content of the filters were determined as previously described (Cullis, 1979a).

\section{(vii) Extraction, electrophoresis and staining of peroxidase isozymes}

Stem extracts were prepared and the electrophoresis and staining carried out as previously described (Cullis, 1979b).

\section{REsults}

\section{(i) Characteristics of $P l$}

The two lines of PI derived from the two separate capsules had different characteristics. One line had hairy septa and an rDNA amount of $1.03 \pm$ 0.06 per cent (termed Pl1). The other line had hairless septa, was taller than Pl1 and had an rDNA amount of $0.83 \pm 0.03$ per cent (termed Pl2). Since the original plastic line described by Durrant (1971) had hairy septa, Pl1 was used as the parental line for the induction experiments described here.

\section{(ii) Induction in plants grown in soil based compost}

Pl1 was sown in a soil based compost watered with either npk, nk or tap water. For comparison Pl1 was also grown in JIP1. There were differences in growth in the three nutrient environments, with the plants given npk being the most, and those without added nutrients the least, vigorous. Seeds were collected from ten individual plants grown in each of the three environments and five seeds from each plant planted singly in 5 inch pots in JIP1. 
The progeny from each treatment were very uniform in height but there were differences between the treatments. Progeny from treated plants are shown in fig. 1. Those grown in npk were the tallest $(120 \pm 5 \mathrm{~cm})$, (the progeny from one of these plants was termed $\mathrm{C} 1$ ), those grown in nk were intermediate $(107 \pm 5 \mathrm{~cm}$ ), (the progeny from one of these plants was termed C2) while those grown without fertilizer were shortest $(82 \pm 6 \mathrm{~cm})$, (the progeny from one of these lines was termed $\mathrm{C} 3$ ). The peroxidase isozyme band pattern of the progeny from plants grown in npk and nk were identical to each other and to that observed previously for the $\mathrm{L}$ genotroph (Cullis and Kolodynska, 1975). The peroxidase band pattern for the progeny of plants grown without added fertilizers was the same as that for the $S$ genotroph (fig. 2).

The proportion of the DNA homologous to the 25S and 18S rRNA was determined for the progeny of one plant from each of the treatments. The results are given in table 1 . It can be seen that the values for $\mathrm{C} 1$ and $\mathrm{C} 2$ are similar to one another $(0.79$ per cent, 0.82 per cent $)$ and greater than the value for $C 3(0.39$ per cent $)$. However all these families had lower rDNA amounts than P11 grown in JIP1 (1.03 per cent).

TABLE 1

\begin{tabular}{|c|c|c|}
\hline & \multirow{2}{*}{\multicolumn{2}{|c|}{$\begin{array}{l}\text { rDNA amounts of progeny Pl1 plants grown un } \\
\text { various fertilizer regimes in soil based compo }\end{array}$}} \\
\hline 4008 & & \\
\hline 4010 & $\begin{array}{c}\text { Fertilizer regime } \\
\text { (Progeny designation) }\end{array}$ & rDNA $(\%)$ \\
\hline 4011 & JIP1 (PI1) & $1.03 \pm 0.06$ \\
\hline 4012 & npk (C2) & $0.79 \pm 0.06$ \\
\hline 4013 & nk (C2) & $0.82 \pm 0.04$ \\
\hline 4014 & (C3) & $0.39 \pm 0.03$ \\
\hline
\end{tabular}

The large reduction in rDNA amount and the change in peroxidase isozyme band pattern observed in $\mathrm{C} 3$ was not repeatable in subsequent sowings of $\mathrm{Pl} 1$ in soil based compost to which no fertilizer solutions were applied. Two independent sets of plants were grown in such an environment and the mean rDNA amount of all the progeny was $0.73 \pm 0.08$. (The rDNA was determined for 2 individual plants from each of the progeny of 28 plants grown in this inducing environment). It can be seen that there was a reduction in the rDNA level but it was not as large as observed in C3. In addition none of the progeny (progeny from 18 of the 28 treated plants were tested) showed the S-type peroxidase pattern. The only known difference between the growing conditions of these two sets of plants and that inducing C3 was the loam used to make the compost.

Thus the growth conditions described above induced changes in the rDNA and/or the isozyme band pattern in the progeny of plants grown under these conditions. However these changes were not repeatable in their extent. It would appear that a reduction in rDNA amount was a very common event, while the change in isozyme band pattern was much rarer.

\section{(iii) Induction in plants grown in inert supporting medium}

To overcome the problems possibly caused by different ingredients in the soil-based composts described in the previous section, plants of Pl1 


\section{Plate I}

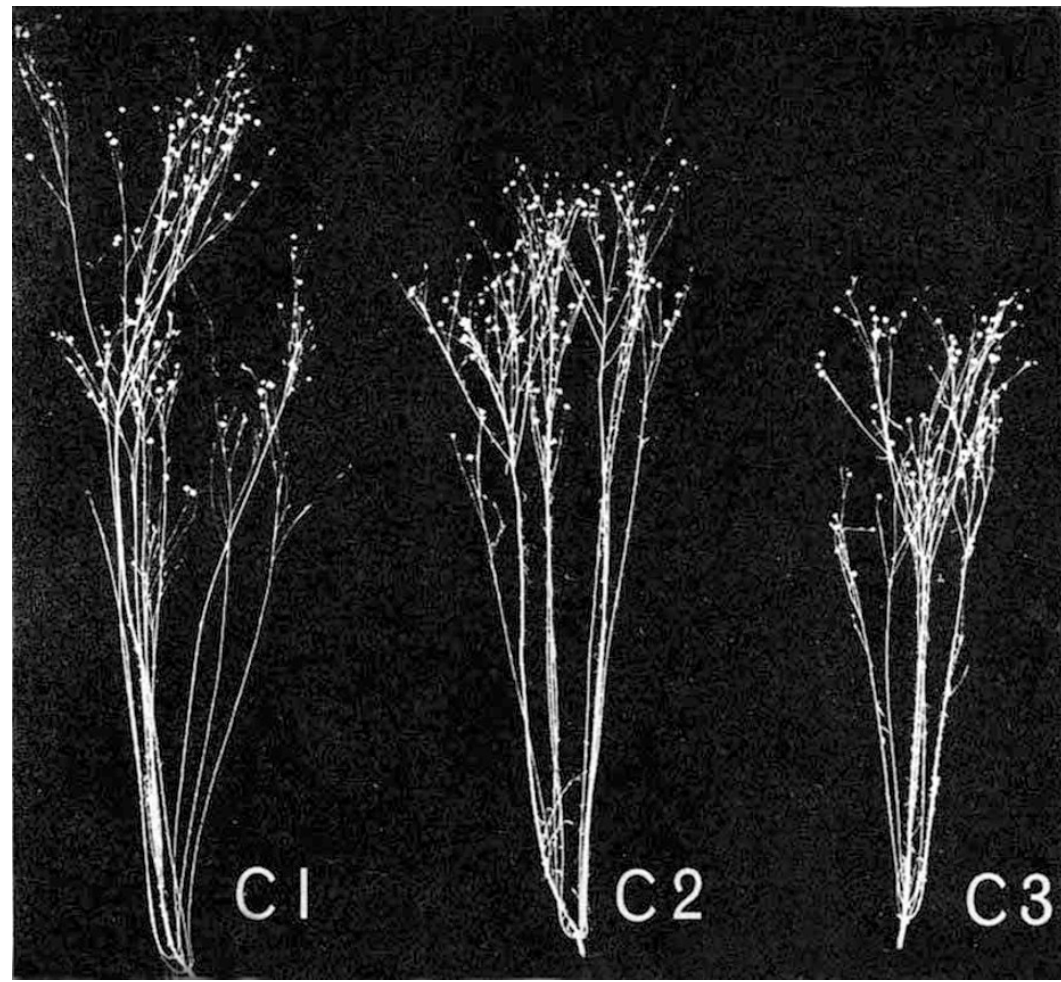

FIG. 1.-Progeny of Pl1 plants grown in npk (C1), nk (C2) and nil (C3). The progeny were all grown under the same conditions. 


\section{Plate II}

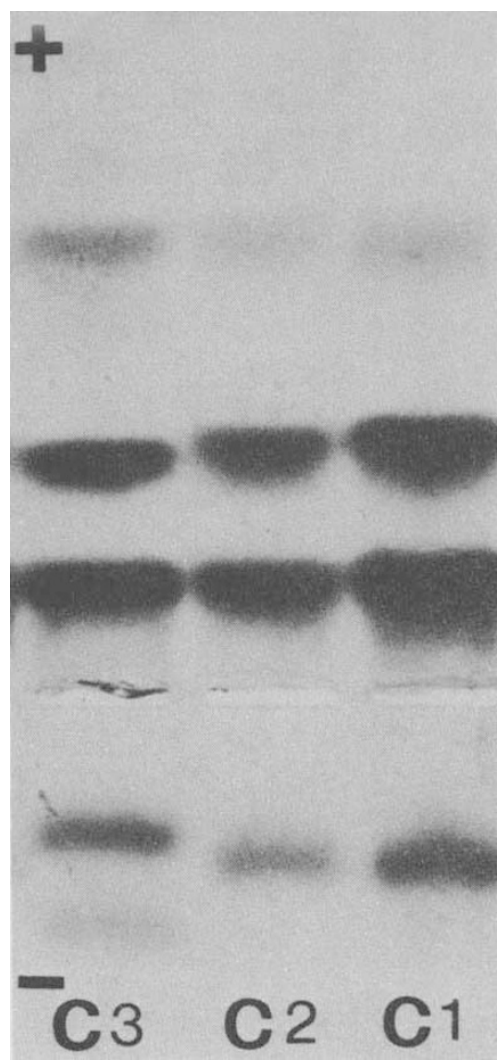

FIG. 2.-Peroxidase isozyme band pattern of $\mathrm{C} 3, \mathrm{C} 2$ and $\mathrm{C} 1$ (see Fig. 1) all grown under the same conditions. 
were grown singly in perlite/chick grit in 5 inch pots under various nutrient regimes (see Materials and Methods). Plants were grown under the appropriate conditions and seeds from 5 individual plants from each treatment, except treatment 2 , were grown in the greenhouse in JIP1. The effect of treatment 2 could not be tested as no seed was set (the flowers abort at an early stage) although this environment was conducive to the most vigorous growth. The rDNA amounts of the progeny of different plants from each of the treatments are given in table 2 . The values are

\section{TABLE 2}

rDNA amounts of the progeny of Pl1 grown under various nutrient regimes in perlite/chick grit

\begin{tabular}{|c|c|c|c|}
\hline Nutrient regime & Treated Plant Number & rDNA of progeny (\%) & Mean \\
\hline 1 & $\begin{array}{l}1 \\
2 \\
3 \\
4 \\
5\end{array}$ & $\begin{array}{l}0.71 \\
0 \cdot 72 \\
0.69 \\
0 \cdot 74 \\
0 \cdot 71\end{array}$ & $0.71 \pm 0.02$ \\
\hline 3 & $\begin{array}{l}1 \\
2 \\
3 \\
4 \\
5\end{array}$ & $\begin{array}{l}0 \cdot 70 \\
0 \cdot 82 \\
0 \cdot 72 \\
0 \cdot 74 \\
0 \cdot 77\end{array}$ & $0.75 \pm 0.05$ \\
\hline 4 & $\begin{array}{l}1 \\
2 \\
3 \\
4\end{array}$ & $\begin{array}{l}0.67 \\
0.64 \\
0.66 \\
0.74\end{array}$ & $0.68 \pm 0.04$ \\
\hline 5 & $\begin{array}{l}1 \\
2 \\
3 \\
4 \\
5\end{array}$ & $\begin{array}{l}0 \cdot 63^{\mathrm{a}} \\
0 \cdot 76^{\mathrm{a}} \\
0 \cdot 61^{\mathrm{a}} \\
0 \cdot 77 \\
0 \cdot 68\end{array}$ & $0.69 \pm 0.07$ \\
\hline 6 & $\begin{array}{l}1 \\
2 \\
3 \\
4 \\
5\end{array}$ & $\begin{array}{l}0 \cdot 69 \\
0 \cdot 71 \\
0 \cdot 71 \\
0 \cdot 80 \\
0 \cdot 75\end{array}$ & $0 \cdot 73 \pm 0 \cdot 04$ \\
\hline
\end{tabular}

the means of duplicate filters of two independent DNA preparations each made from the pooled leaf material from 2 plants. It can be seen that in all the environments there was a reduction in the rDNA amount. However in no case was there as large a reduction as that observed in $\mathrm{C} 3$.

The isozyme band pattern for peroxidase was determined on the stem from each of 5 progeny plants from the individual treated plants described above. No changes were observed in the progeny of plants grown in treatments 1, 3, 4 and 6 (100 plants tested) while 3 out of 5 families from treatment 5 showed altered peroxidase isozymes, that is showed the $S$ type pattern (fig. 3e) (25 plants tested, 15 showed altered isozymes). All the plants, in a particular family, showed the same isozyme band pattern.

The progeny of a further 10 plants grown under treatment 5 in an independent experiment were grown in JIP1 in the greenhouse and their rDNA amounts and peroxidase isozyme band pattern determined. All 
showed a reduced rDNA amount $(0 \cdot 80 \pm 0 \cdot 07)$ while 7 of the 10 families showed an altered peroxidase isozyme band pattern.

\section{(iv) Changes in isozyme band pattern during growth in inducing environments}

The mobility of certain of the peroxidase isozyme bands is dependent on the age of the part of the stem from which they are extracted (Fieldes, Tyson and Bashour, 1976), so that a comparison between plants requires equivalent stem sections to be taken. Parts of the stem at all stages of growth of plants grown in treatment 5 were extracted and the peroxidase isozyme band pattern determined. When equivalent stem sections were compared, no changes could be found in any of the plants tested, including the extractable peroxidases from the dried peduncle (fig. $3 a, b$ ). However as stated earlier when the seeds from these plants were grown, one set of progeny (from plant No. 3) had the $S$ type peroxidase pattern while the other (from plant No. 4) showed an unchanged pattern (fig. 3e,f). Although not all the peroxidase bands could be visualised in the dried peduncle, it has previously been shown that the altered isozyme bands are inherited as a single unit (Cullis, 1979 $\mathrm{b}$ ), so that any one band should be a sufficient marker. Thus no evidence could be found for a change in the isozyme band pattern during growth in the inducing environment, although changes were observed in the progeny of plants grown in that environment.

\section{Discussion}

A number of characters have been shown to be susceptible to environmentally induced heritable changes and many of these can occur independently (Cullis, 1977). Thus the judgement as to whether an environment is capable of inducing heritable changes in a particular variety of flax is dependent on the specific character studied.

The results reported here demonstrated that all the environments tested, with the exception of the JIP1 growing medium, resulted in a change in the rDNA level. The validity of the JIP1 environment was a non-inducing environment is supported by the following; the rDNA level of young plants of Pl1 grown in a variety of environments (Cullis and Charlton, 1981), and the level in the progeny of Pl1 grown in JIP1 (this paper) is always the same. As the rDNA level does not change in successive generations of P11 grown in JIP1, the rDNA levels of plants which were grown under different environments can be compared with the level in Pl1 grown in JIP1. On this basis most environments induced a reduction in the rDNA amount, many to a similar level, 20-30 per cent below the level found in P11. This value may have been a consequence of the way in which the rDNA reduction had occurred. No environments have been found which induce increased rDNA amounts in subsequent generations, although treatment 2 induced increases in the rDNA amount during growth in this environment (Cullis and Charlton, 1981).

The original $\mathrm{L}$ and $\mathrm{S}$ genotrophs were induced by npk and nk treatments respectively (Durrant, 1962). The rDNA amounts of these two genotrophs were $0.79 \pm 0.06$ and $0.58 \pm 0.05$ (Cullis, 1979a). Thus the particular treatments used here did not produce exactly comparable effects to those seen previously (Durrant, 1962). 


\section{Plate III}
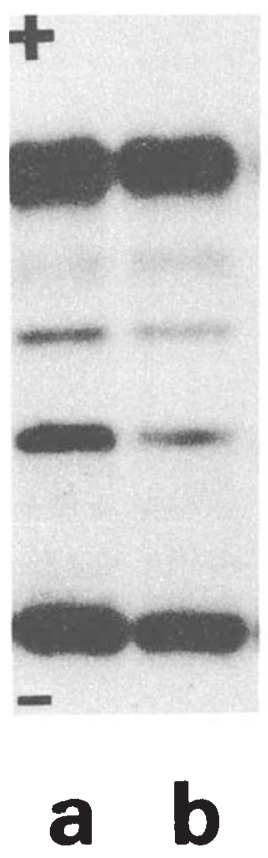
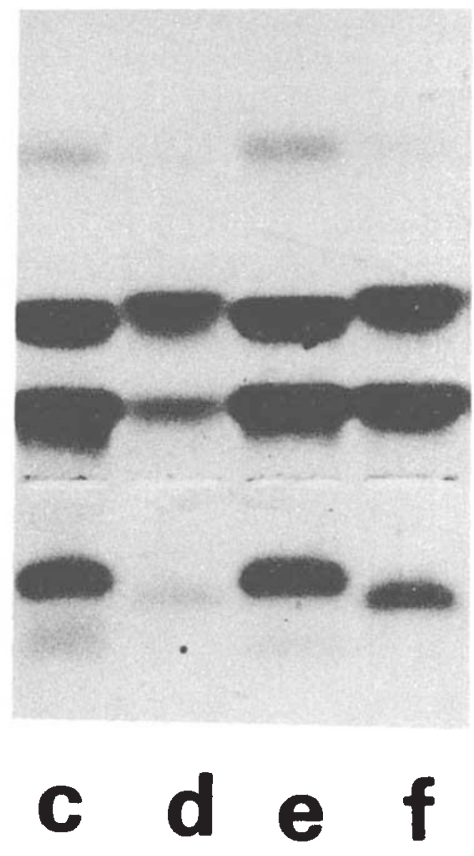

FIG. 3.-Peroxidase isozyme band patterns of plants growing under treatment 5, and the progeny of those piants. (a)-(b) Isozyme pattern of peduncle of plants numbered 3 and 4 respectively growing under treatment 5 . (c)-(f) Plants growing in JIP1 (c) S genotroph. (d) L genotroph, (e) Progeny from plant No. 3 above (f) Progeny from plant No. 4 above. 
The peroxidase isozyme band pattern observed for Pl1 was the same as that previously described as the L-type pattern, and was dominant to the altered S-type band pattern (Cullis, 1979b). There were three major differences between the induction of changes in isozyme band pattern and changes in rDNA amount. Firstly changes in the isozymes were not as frequent as changes in rDNA. Secondly, changes were only induced in the progeny of some of the plants grown in a particular environment. However in families in which changes were observed, all the progeny tested showed the altered isozyme band pattern. Thirdly there was no evidence for the expression of the changed phenotype during growth in the inducing environment. This last observation places constraints on the timing of the changes which caused the variation in the isozymes. If the changes occurred at or close to the time of meiosis, then it must have occurred in all or almost all the germ line cells since the altered pattern is recessive (Cullis, 1979b). Alternatively, if the induced changes occurred early, then the expression of the altered phenotype must have been repressed during the growth under inducing conditions.

The experiments reported here confirm that changes in rDNA and peroxidase isozymes can be induced independently. However the mechanism by which these induced changes occur still remains obscure. There are at least two possibilities for the mechanism by which the rDNA change occurs. One is via an extrachromosomal intermediate and the other is by unequal mitotic recombination followed by cell selection. If the former mechanism is correct, the origin of the extrachromosomal copies must be explained. The results in this paper can be explained if the PI1 line has 20-30 per cent of its rDNA in an extrachromosomal state and the environments tested here generally cause this material to be lost. This would account for the apparent preferred level of reduction observed. Only in particular environments, so far unspecified, would a further reduction occur, with the appearance of genotrophs such as C3. This same extrachromosomal material could be the basis of the amplification observed during growth of Pl1 under treatment 2 (Cullis and Charlton, 1981). This hypothesis is testable and Pl1 grown under a number of environments is currently being examined for the presence of extrachromosomal rDNA.

The changes in rDNA amount and peroxidase isozymes are not always associated, and the question which arises is whether or not the two changes are caused by a common mechanism. It has been proposed that the changes in peroxidase isozymes may be caused by a DNA rearrangement, possibly mediated by some form of transposable element (Cullis, 1977; 1979b). However in all the examples studied, the change in peroxidase has been from $L$ type to $S$ type, and never the reverse. Thus the rearrangement may not be directly reversible, possibly due to a deletion of material at or near the site of the rearrangement. Such deletions have been demonstrated during the integration of transposable elements in prokaryotes (Starlinger and Saedler, 1976). The occurrence of transposable elements in flax would validate the basis for this proposal and cloned variable sequences in flax are presently being investigated.

Acknowledgements.-I would like to thank Miss L. Charlton for her excellent technical assistance. 


\section{REFERENCES}

CULlis, C. A. 1975. Environmentally induced DNA differences in flax. In Modification of the information content of plant cells, eds. R. Markham, D. R. Davies, D. A. Hopwood, and R. W. Horne, pp. 27-36. North Holland, Amsterdam.

CULLIS, C. A. 1976. Environmentally induced changes in ribosomal RNA cistron number in flax. Heredity, 36, 73-79.

CULLIS, C. A. 1977. Molecular aspects of the environmental induction of heritable changes in flax. Heredity, 38, 129-154.

CULLIS, C. A. $1979 a$. Quantitative variation of ribosomal RNA genes in flax genotrophs. Heredity, 42, 237-246.

CULlis, C. A. 1979b. Segregation of the isozymes of flax genotrophs. Biochem. Genet., 17, $391-401$.

CULlis, C. A., AND CHARLTON, L. 1981. The induction of ribosomal DNA changes in flax. Plant Sci. Lett., 20, 213-217.

CULlis, C. A., AND KOLODYNSKA, K. 1975. Variation in the isozymes of flax (Linum usitatissimum) genotrophs. Biochem. Genet., 13, 687-697.

DURRANT, A. 1962. The environmental induction of heritable changes in Linum. Heredity, 17, 27-61.

DURRAN1, A. 1971. Induction and growth of flax genotrophs. Heredity, 27, 277-298.

DURRANT, A., AND JONES, T. W. A. 1971. Reversion of the induced changes in amount of DNA in Linum. Heredity, 27, 431-439.

DURRANT, A., AND NICHOLAS, D. B. 1970. An unstable gene in flax. Heredity, 25,513-527.

EVANS, G. M.. DURRANT, A., AND REES, H. 1966. Associated nuclear changes in the induction of flax genotrophs. Nature, 212, 697-699.

FIELDES, M. A., TYSON, H., AND BASHOUR, N. 1976. Relative shifts in Mobility in anionic peroxidase isozymes between stem base and apex of flax genotrophs. Phytochem., 15, 247-250.

MURASHIGE, T., AND SKOOG, F. 1962. A revised medium for rapid growth and bioassays with tobacco tissue cultures. Physiologia Pl., 15, 473-497.

STARLINGER, P., AND SAEDLER, H. 1976. IS elements in microorganisms. Current topics Microbiol. Imm., 75, 111-152. 